\title{
Glass formation domains and structural properties of nonconventional transition metal ion glasses
}

\section{A GHOSH}

Solid State Physics Department, Indian Association for the Cultivation of Science, Calcutta 700032 , India

\begin{abstract}
Glass formation domains and structural properties of some binary transition metal ion glasses based on nonconventional network formers $\mathrm{Bi}_{2} \mathrm{O}_{3}$ and $\mathrm{PbO}$ have been investigated. With the same network former, the glass formation domains depend on the transition metal ions. Homogeneous glasses with random network structure were obtained, as evidenced by the composition dependent density, molar volume and glass transition temperatures. Significant information about possible structural units in these glasses has been obtained from the IR spectra of these glasses.
\end{abstract}

Keywords. Glass formation domain; transition metal; nonconventional glass; glass transition temperature; molar volume; density; IR spectra.

\section{Introduction}

Oxide glasses based on nonconventional network formers like $\mathrm{PbO}$ and $\mathrm{Bi}_{2} \mathrm{O}_{3}$ are of great interest because they form amorphous materials without traditional network formers like $\mathrm{P}_{2} \mathrm{O}_{5}, \mathrm{~B}_{2} \mathrm{O}_{3}, \mathrm{GeO}_{2}, \mathrm{SiO}_{2}$ etc and they can be used to produce glassceramics, layers for optical and optoelectronic devices, thermal and mechanical sensors, reflecting windows etc (Dimitriev et al 1986; Mianxve and Peinan 1986; Aegerter et al 1990; Takahashi and Yamaguchi 1990). Fajans and Kreidl (1948) pointed out that $\mathrm{Pb}^{2+}$ and $\mathrm{Bi}^{3+}$ cations are highly polarizable and the asymmetry of their polyhedra inhibits crystallization processes in the melts in which they participate. Multicomponent glasses based on $\mathrm{PbO}$ or $\mathrm{Bi}_{2} \mathrm{O}_{3}$ have been successfully synthesized and their structures studied (Bishay and Maghrabi 1969; Dumbaugh 1978, 1986; Morikawa et al 1981; Rao et al 1984; Dimitriev et al 1986). The recently reported (Zheng and Mackenzie 1988; Tatsumisago et al 1990; Onisi et al 1991; Yuan et al 1991) multicomponent cuprate glasses in which $\mathrm{Bi}_{2} \mathrm{O}_{3}$ is the main glass former are of particular interest because they can be used to produce high temperature superconductor glass-ceramics with controllable microstructure. In this paper, glass formation domains and structural properties of some $\mathrm{Bi}_{2} \mathrm{O}_{3}$ and $\mathrm{PbO}$ based nonconventional binary glasses containing transition metal ions such as $\mathrm{V}, \mathrm{Fe}$ and $\mathrm{Cu}$ have been discussed. It is worth mentioning that these glasses exhibit semiconducting properties arising from the presence of multivalent states of the transition metal ions in the glassy materials and thus, have many applications, such as memory and threshold switching, ferrites, cathode materials, etc (Nakamura and Ichinose 1987; Ghosh 1988; Livage et al 1990; Sakuri and Yamaki 1990).

\section{Experimental}

Different binary glass compositions studied were prepared from reagent grade chemicals $\mathrm{Bi}_{2} \mathrm{O}_{3}, \mathrm{PbO}, \mathrm{V}_{2} \mathrm{O}_{5}, \mathrm{Fe}_{2} \mathrm{O}_{3}$ and $\mathrm{CuO}$. The binary mixtures of the 
appropriate chemicals were melted in alumina crucibles for $2 \mathrm{~h}$ at temperatures depending on compositions. Glasses were obtained either by pouring the melts onto a twin-roller or by pressing the melts between two brass plates depending on glass systems and compositions. All the prepared glasses were tested for their amorphous structure using $\mathrm{X}$-ray diffraction and scanning electron microscopy. Glass transition and crystallization temperatures were obtained from differential thermal analysis. Density was measured using Archimedes' principle. The IR spectra of these glasses in $\mathrm{KBr}$ matrices were recorded in the range $200-4000 \mathrm{~cm}^{-1}$ in a Perkin-Elmer spectrophotometer. Final glass compositions were estimated either by atomic absorption or by chemical analysis. The concentrations of the reduced transition metal ions were determined by either chemical analysis or magnetic measurements.

\section{Results and discussion}

\subsection{Glass formation domain}

Two systems of glasses of compositions $(\mathrm{PbO})_{1-x}(\mathrm{TMO})_{x}$ and $\left(\mathrm{Bi}_{2} \mathrm{O}_{3}\right)_{1-x}(\mathrm{TMO})_{x}$, where TMO $=\mathrm{V}_{2} \mathrm{O}_{5}, \mathrm{Fe}_{2} \mathrm{O}_{3}$ and $\mathrm{CuO}$ and $x$ is the mol fraction of TMO, were studied. The glass formation domains for these two systems of glasses are shown in figure 1. It is clear that among the $\mathrm{PbO}$ based glasses, the glass formation domain $0.25 \leqslant x \leqslant 0.90$ for the $\mathrm{PbO}-\mathrm{V}_{2} \mathrm{O}_{5}$ system is the largest, while the domain $0.05 \leqslant x \leqslant 0.30$ is the smallest for the $\mathrm{PbO}-\mathrm{Fe}_{2} \mathrm{O}_{3}$ glasses. The $\mathrm{PbO}-\mathrm{CuO}$ glasses have intermediate glass formation domain $0.15 \leqslant x \leqslant 0.50$. On the other hand, for the $\mathrm{Bi}_{2} \mathrm{O}_{3}$ based glasses, the $\mathrm{Bi}_{2} \mathrm{O}_{3}-\mathrm{CuO}$ system has the largest glass formation domain $0 \cdot 25 \leqslant x \leqslant$ 0.70 , while the glass formation domain $0.70 \leqslant x \leqslant 0.95$ is the smallest for the $\mathrm{Bi}_{2} \mathrm{O}_{3}$ $\mathrm{V}_{2} \mathrm{O}_{5}$ glasses. The glass formation domain for the $\mathrm{Bi}_{2} \mathrm{O}_{3}-\mathrm{Fe}_{2} \mathrm{O}_{3}$ system is the same as for $\mathrm{PbO}-\mathrm{Fe}_{2} \mathrm{O}_{3}$ system. However, a larger glass formation domain for the $\mathrm{Bi}_{2} \mathrm{O}_{3}$ $\mathrm{Fe}_{2} \mathrm{O}_{3}$ system has been reported using much faster quenching rate (Tanaka et al 1989). It is noted that glass formation occurs in the $\mathrm{Bi}_{2} \mathrm{O}_{3}-\mathrm{V}_{2} \mathrm{O}_{5}$ system for higher $\mathrm{V}_{2} \mathrm{O}_{5}$ content.

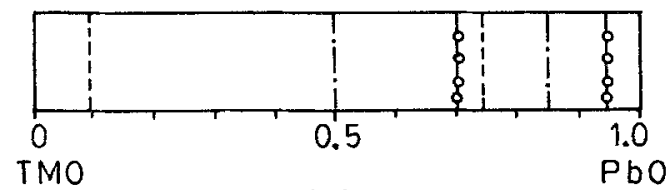

(a)

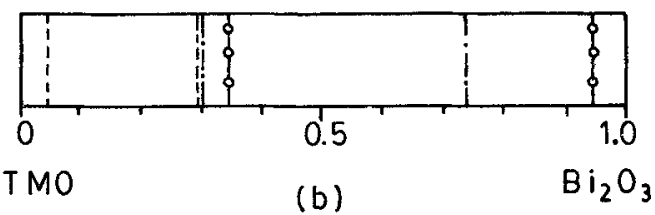

Figure 1. Glass formation domains for (a) $\mathrm{PbO}$-TMO systems and (b) $\mathrm{Bi}_{2} \mathrm{O}_{3}-\mathrm{TMO}$ systems. Domain boundaries are shown by ${ }_{1}^{\prime}$ for $\mathrm{V}_{2} \mathrm{O}_{5} ; \uparrow$ for $\mathrm{Fe}_{2} \mathrm{O}_{3}$ and ${ }_{i}$ for $\mathrm{CuO}$ glasses. 


\subsection{Analyzed glass compositions}

Wet chemical and atomic absorption spectroscopic analysis showed that all glass compositions changed slightly from the batch compositions due to evaporation loss. These measurements coupled with the magnetic measurements indicated that in all glass compositions, transition metal ions exist in two oxidation states, e.g. $\mathrm{V}^{4+}$ and $\mathrm{V}^{5+}, \mathrm{Cu}^{+}$and $\mathrm{Cu}^{2+}$ and $\mathrm{Fe}^{2+}$ and $\mathrm{Fe}^{3+}$ for the vanadate, cuprate and ferric glasses, respectively. However, the concentrations of the reduced ions depend on the glass compositions. The fraction of the reduced ion concentration was observed to be the highest for cuprate glasses, while it was the lowest for ferric glasses.

\subsection{Density and molar volume}

The variation of density and molar volume of the two systems of glasses are shown in figures 2 and 3 respectively. It is clear from figure $2 \mathrm{a}$ that for the $\mathrm{PbO}$ based glasses, the density increases with the increase of $\mathrm{PbO}$ content. The density for the $\mathrm{PbO}-$ $\mathrm{CuO}$ glasses is higher than that for the $\mathrm{PbO}-\mathrm{V}_{2} \mathrm{O}_{5}$ glasses. For the $\mathrm{Bi}_{2} \mathrm{O}_{3}$ based glasses, the variation of density with composition is small for all glass compositions (figure 2b). The density of $\mathrm{Bi}_{2} \mathrm{O}_{3}-\mathrm{CuO}$ glasses is comparable with that of the $\mathrm{Bi}_{2} \mathrm{O}_{3}-\mathrm{Fe}_{2} \mathrm{O}_{3}$ glasses, while the density for the $\mathrm{Bi}_{2} \mathrm{O}_{3}-\mathrm{V}_{2} \mathrm{O}_{5}$ glasses is the lowest. On the other hand, the variation of the molar volume of the $\mathrm{PbO}-\mathrm{CuO}$ glass system (figure 3a) with composition shows opposite trends to the variation of density, while for the other glass systems (figures $3 a$ and $b$ ), molar volume changes with composition in a fashion similar to the density. Thus for the glass systems studied, except for $\mathrm{PbO}-\mathrm{V}_{2} \mathrm{O}_{5}$ with $\mathrm{PbO}$ content $>50 \mathrm{~mol} \%$, the density and the molar volume change monotonically with composition. This indicates that all the glass systems are probably in a single phase with random network structure and that the geometry and topology of the random network do not change significantly with compositions.

\subsection{Glass transition temperatures}

The glass transition temperatures $\left(T_{\mathrm{g}}\right)$ determined from the differential thermal analysis curves are shown in figure 4 , as a function of compositions. Figure $4 \mathrm{a}$ indicates
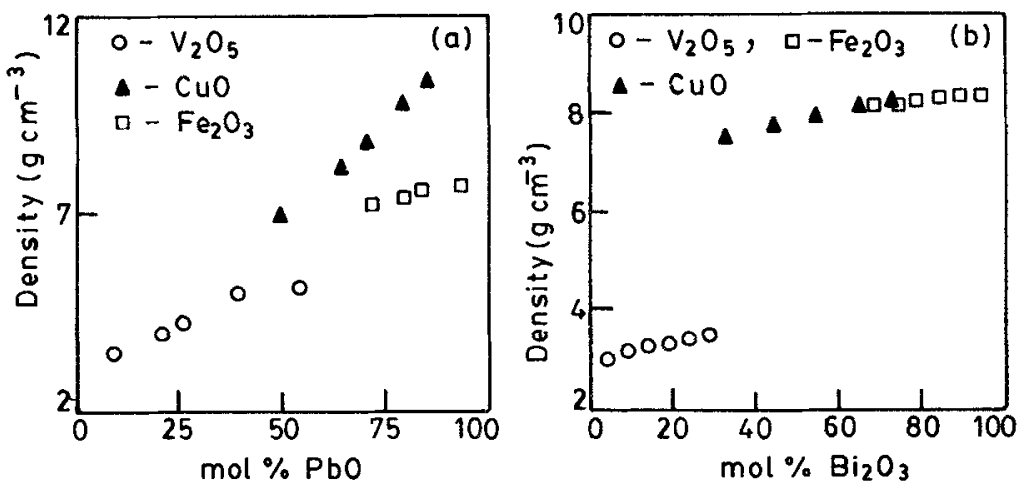

Figure 2. Variation of density with glass composition: (a) PbO-TMO glasses and (b) $\mathrm{Bi}_{2} \mathrm{O}_{3}-\mathrm{TMO}$ glasses. 

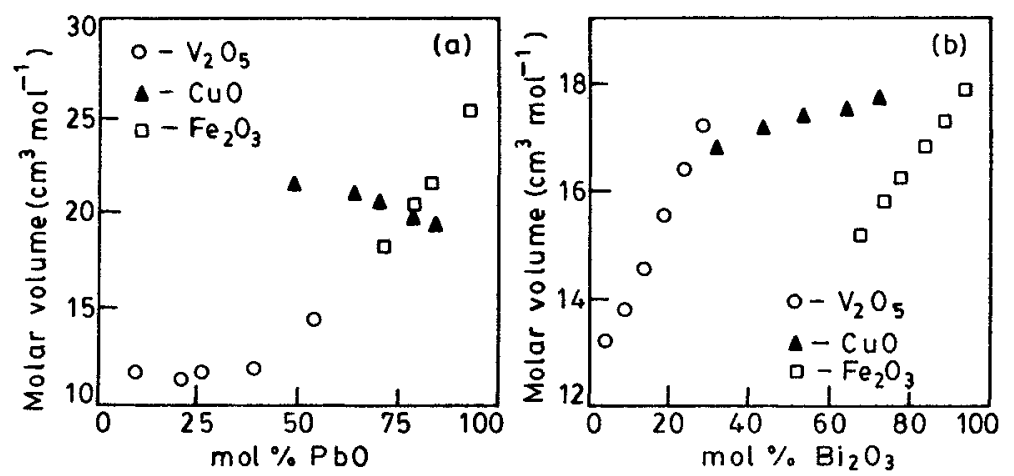

Figure 3. Variation of molar volume with glass compositions: (a) PbO-TMO glasses and (b) $\mathrm{Bi}_{2} \mathrm{O}-\mathrm{TMO}$ glasses.
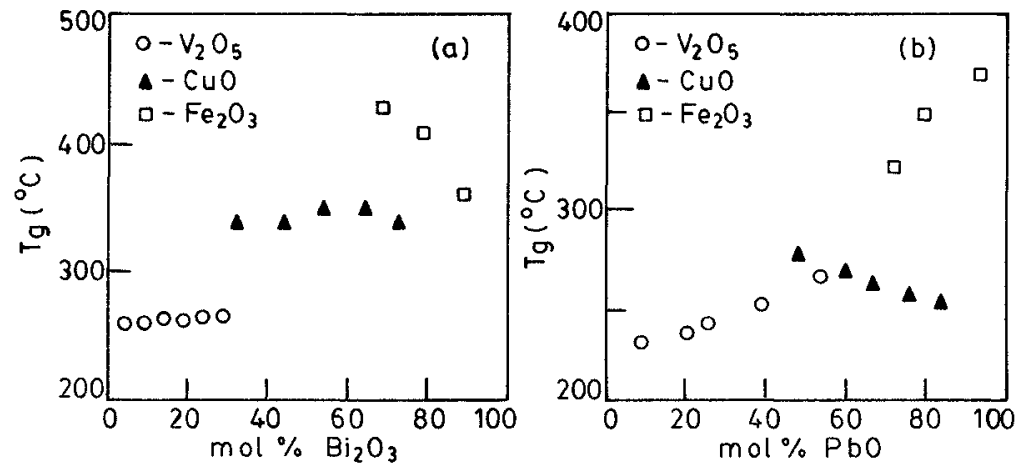

Figure 4. Composition dependence of the glass transition temperature $\left(T_{\mathrm{g}}\right)$ : (a) $\mathrm{Bi}_{2} \mathrm{O}_{3}-\mathrm{TMO}$ glasses and (b) $\mathrm{PbO}-\mathrm{TMO}$ glasses.

that the $T_{\mathrm{g}}$ increases with $\mathrm{Bi}_{2} \mathrm{O}_{3}$ content in the $\mathrm{Bi}_{2} \mathrm{O}_{3}-\mathrm{V}_{2} \mathrm{O}_{5}$ and $\mathrm{Bi}_{2} \mathrm{O}_{3}-\mathrm{CuO}$ glasses, while $T_{\mathrm{g}}$ decreases for the $\mathrm{Bi}_{2} \mathrm{O}_{3}-\mathrm{Fe}_{2} \mathrm{O}_{3}$ glasses. The $T_{\mathrm{g}}$ also increases with $\mathrm{PbO}$ content in $\mathrm{PbO}-\mathrm{V}_{2} \mathrm{O}_{5}$ and $\mathrm{PbO}-\mathrm{Fe}_{2} \mathrm{O}_{3}$ systems while $T_{\mathrm{g}}$ decreases slightly for the $\mathrm{PbO}-\mathrm{CuO}$ system (figure $4 \mathrm{~b}$ ). Since glass transition temperature depends on the strength and connectivity of the network, it is clear from figure 4 that the strength and connectivity of the network increase with the increase of $\mathrm{PbO}$ or $\mathrm{Bi}_{2} \mathrm{O}_{3}$ content in all glass systems except for the $\mathrm{Bi}_{2} \mathrm{O}_{3}-\mathrm{Fe}_{2} \mathrm{O}_{3}$ systems. In the $\mathrm{Bi}_{2} \mathrm{O}_{3}-\mathrm{CuO}$ and $\mathrm{PbO}-\mathrm{CuO}$ systems, however, the variation of $T_{\mathrm{g}}$ with composition is small. The effect of the coulombic field of substitution can account for such a small variation in $T_{\mathrm{g}}$. The increase of $T_{\mathrm{g}}$ with $\mathrm{Bi}_{2} \mathrm{O}_{3}$ or $\mathrm{PbO}$ content in the vanadate glass system also suggest a continuous change of the glass matrix having a $2 \mathrm{D}$ vanadate layer structure into a more complicated 3D structure (Mandal and Ghosh 1993). These conclusions are also supported by the IR results.

\subsection{Infrared spectra}

Infrared (IR) spectra of the glass compositions yield important information about structural units. The spectra of several glass compositions have been reported elsewhere 


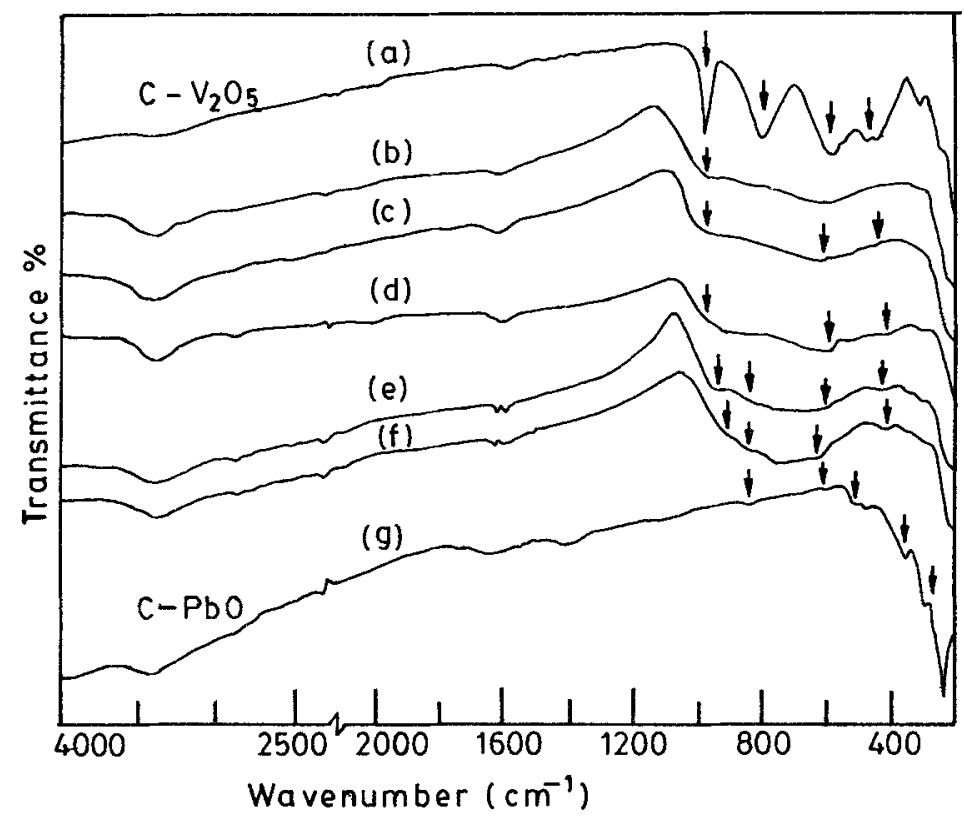

Figure 5. Room temperature IR spectra of $\mathrm{PbO}-\mathrm{V}_{2} \mathrm{O}_{5}$ glasses: (a) Crystalline $\mathrm{V}_{2} \mathrm{O}_{5}$, (b) $90 \mathrm{~mol}^{\circ} \mathrm{V}_{2} \mathrm{O}_{5}$, (c) $80 \mathrm{~mol} \% \mathrm{~V}_{2} \mathrm{O}_{5}$, (d) $70 \mathrm{~mol}_{\mathrm{o}} \mathrm{V}_{2} \mathrm{O}_{5}$, (e) $60 \mathrm{~mol}^{\circ} \mathrm{v}_{2} \mathrm{O}_{5}$, (f) $50 \mathrm{~mol} \%$ $\mathrm{V}_{2} \mathrm{O}_{5}$ and $(\mathrm{g})$ crystalline $\mathrm{PbO}$.

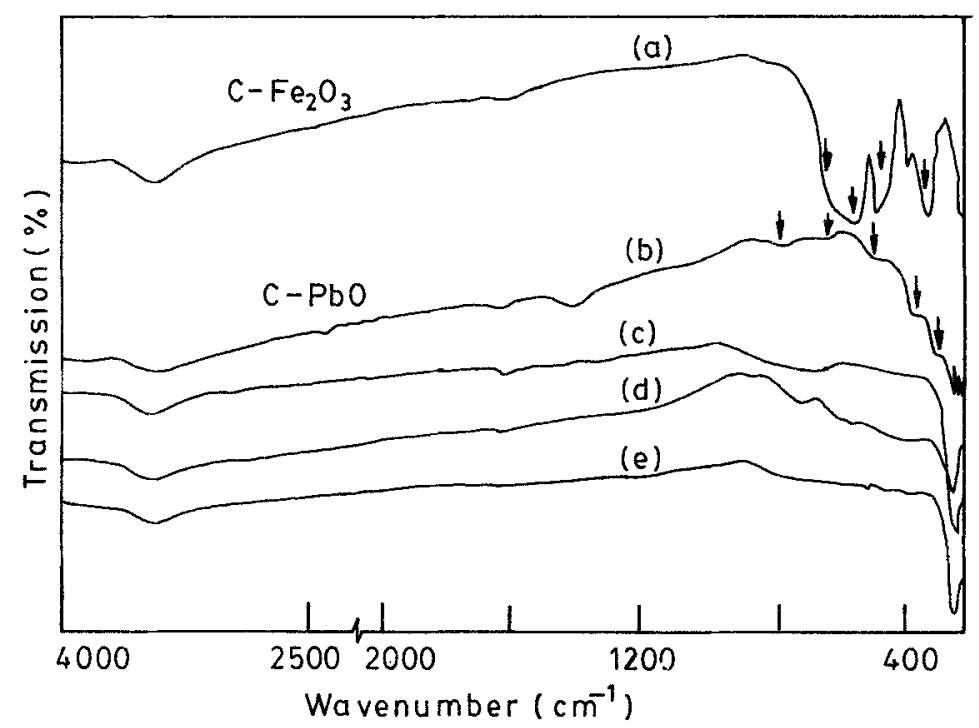

Figure 6. Room temperature IR spectra of $\mathrm{PbO}-\mathrm{Fe}_{2} \mathrm{O}_{3}$ glasses: (a) crystalline $\mathrm{Fe}_{2} \mathrm{O}_{3}$, (b) crystalline $\mathrm{PbO}$, (c) $10 \mathrm{~mol}_{\%} / \mathrm{Fe}_{2} \mathrm{O}_{3}$, (d) $15 \mathrm{~mol}_{\%} / \mathrm{Fe}_{2} \mathrm{O}_{3}$ and (e) $20 \mathrm{~mol}_{\%}^{\circ} \mathrm{Fe}_{2} \mathrm{O}_{3}$. 


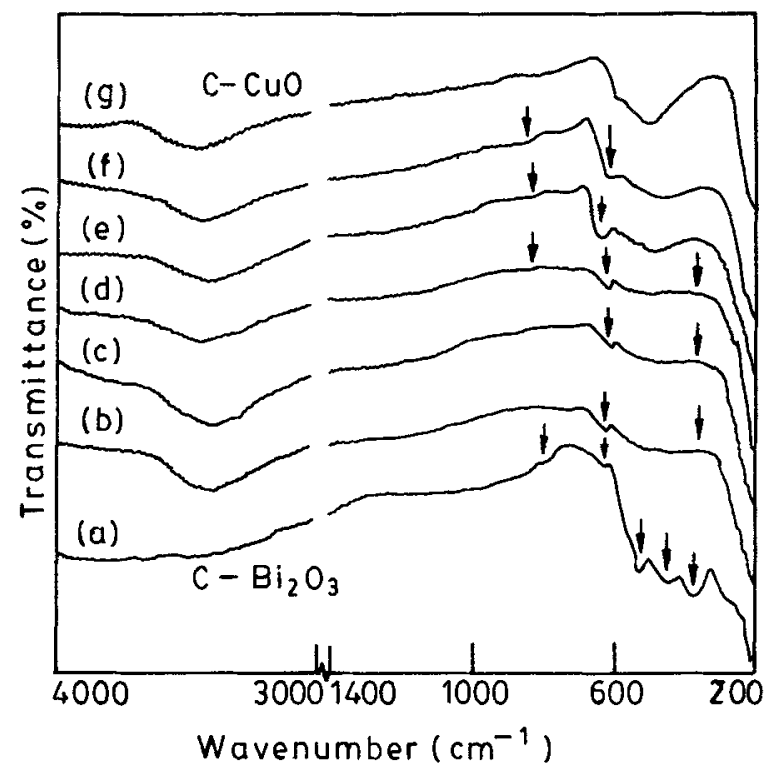

Figure 7. Room temperature IR spectra of $\mathrm{Bi}_{2} \mathrm{O}_{3}-\mathrm{CuO}$ glasses: (a) crystalline $\mathrm{Bi}_{2} \mathrm{O}_{3}$, (b) $27 \mathrm{~mol} \% \mathrm{CuO}$, (c) $35.4 \mathrm{~mol} \% \mathrm{CuO}$, (d) $46 \mathrm{~mol} \% \mathrm{CuO}$, (e) $56 \mathrm{~mol} \% \mathrm{CuO}$, (f) $68 \mathrm{~mol} \% \mathrm{CuO}$ and (g) crystalline $\mathrm{CuO}$.

(Mandal and Ghosh 1993; Hazra and Ghosh 1995). For briefness, IR spectra of three glass systems for different compositions are shown in figures 5-7.

3.5a $\mathrm{PbO}-\mathrm{V}_{2} \mathrm{O}_{5}$ and $\mathrm{Bi}_{2} \mathrm{O}_{3}-\mathrm{V}_{2} \mathrm{O}_{5}$ glass systems: It is clear from the IR spectra of $\mathrm{PbO}-\mathrm{V}_{2} \mathrm{O}_{5}$ glasses presented in figure 6 that the band at $1020 \mathrm{~cm}^{-1}$ for the $\mathrm{V}=\mathrm{O}$ bond vibration of the crystalline $\mathrm{V}_{2} \mathrm{O}_{5}$ becomes very weak for the glass compositions and shifts to lower frequencies with increasing $\mathrm{PbO}$ content. Also new bands appear in the range $950-970 \mathrm{~cm}^{-1}$. For $\mathrm{PbO}$ content $>40 \mathrm{~mol}^{\circ} \%$, the band at $1020 \mathrm{~cm}^{-1}$ vanishes and new bands appear at $950 \mathrm{~cm}^{-1}$ and $430 \mathrm{~cm}^{-1}$. According to the mechanism suggested earlier (Dimitriev et al 1983), the $\mathrm{Pb}^{2+}$ ions occupy position between the $\mathrm{V}-\mathrm{O}-\mathrm{V}$ layers and have a direct influence on the isolated $\mathrm{V}=\mathrm{O}$ bond of the $\mathrm{VO}_{5}$ groups of the crystalline $\mathrm{V}_{2} \mathrm{O}_{5}$. This leads to a drop in the wave numbers down to $970-950 \mathrm{~cm}^{-1}$ for the compositions with $\mathrm{PbO}$ content below $40 \mathrm{~mol} \%$ and thus for these glass compositions, unaffected $\mathrm{VO}_{5}$ polyhedra are preserved along with the affected $\mathrm{VO}_{5}$ polyhedra. However, for glass compositions with $\mathrm{PbO}$ content above $30 \mathrm{~mol} \%$, only affected $\mathrm{VO}_{5}$ polyhedra are present. The IR spectra of the $\mathrm{Bi}_{2} \mathrm{O}_{3}-$ $\mathrm{V}_{2} \mathrm{O}_{5}$ glasses, reported earlier (Ghosh 1987) indicate that the band at $1020 \mathrm{~cm}^{-1}$ for the $\mathrm{V}=\mathrm{O}$ bond vibration in the $\mathrm{VO}_{5}$ polyhedra is observed for glass composition with $95 \mathrm{~mol}_{\%}^{\circ} \mathrm{V}_{2} \mathrm{O}_{5}$. However, with decreasing $\mathrm{V}_{2} \mathrm{O}_{5}$ content, this band becomes very weak shoulder at $1000-980 \mathrm{~cm}^{-1}$. Thus for these compositions, $\mathrm{Bi}^{3+}$ ions occupy positions between vanadate layers and chains and thus affect directly $\mathrm{V}=\mathrm{O}$ bond similar to $\mathrm{Pb}^{2+}$ ions in $\mathrm{PbO}-\mathrm{V}_{2} \mathrm{O}_{5}$ glass compositions.

$3.5 \mathrm{~b} \quad \mathrm{PbO}-\mathrm{Fe}_{2} \mathrm{O}_{3}$ and $\mathrm{Bi}_{2} \mathrm{O}_{3}-\mathrm{Fe}_{2} \mathrm{O}_{3}$ glass systems: As shown in figure 6, the intensity of the absorption bands for the $\mathrm{PbO}-\mathrm{Fe}_{2} \mathrm{O}_{3}$ glass compositions is very 
weak compared to the crystalline $\mathrm{PbO}$ and $\mathrm{Fe}_{2} \mathrm{O}_{3}$. However, weak bands at $820 \mathrm{~cm}^{-1}$ and $630 \mathrm{~cm}^{-1}$ are observed in all glass compositions. These bands also correspond to the bands of crystalline $\mathrm{PbO}$ for $\mathrm{Pb}-\mathrm{O}$ bond vibration in $\mathrm{PbO}_{4}$ tetrahedra. The band at $350 \mathrm{~cm}^{-1}$ corresponding to the orthorhombic $\mathrm{PbO}$ is not observed in the glass compositions. It may be noted from figure 6 that the bands corresponding to the $\mathrm{Fe}-\mathrm{O}$ bond are not significant in the glasses. However, Mössbauer studies (Mandal et al 1994, 1995) indicate the presence of $\mathrm{FeO}_{4}$ tetrahedra in all glass compositions and the $\mathrm{Fe}-\mathrm{O}$ bond covalency is large compared to the conventional ferric glasses.

The IR spectra of the $\mathrm{Bi}_{2} \mathrm{O}_{3}-\mathrm{Fe}_{2} \mathrm{O}_{3}$ glasses have been reported earlier (Ghosh 1987). The bands at $840 \mathrm{~cm}^{-1}, 540-620 \mathrm{~cm}^{-1}, 470 \mathrm{~cm}^{-1}$ and $350 \mathrm{~cm}^{-1}$ are observed in all glass compositions, suggesting that these glasses are built up of $\mathrm{BiO}_{3}$ pyramidal unit similar to $\mathrm{Bi}_{2} \mathrm{O}_{3}-\mathrm{CuO}$ glasses. Mössbauer studies (Tanaka et al 1989) showed that $\mathrm{Fe}$ exists as $\mathrm{Fe}^{3+}$ ions in $\mathrm{FeO}_{4}$ tetrahedra (isomer shift $<0.4 \mathrm{mms}^{-1}$ ) and the covalency of $\mathrm{Fe}-\mathrm{O}$ bond decreases with the increase of $\mathrm{Fe}_{2} \mathrm{O}_{3}$ content in the glass compositions.

\section{$3.6 \mathrm{Bi}_{2} \mathrm{O}_{3}-\mathrm{CuO}$ and $\mathrm{PbO}-\mathrm{CuO}$ glass systems}

For all glass compositions, four fundamental absorption bands at $830 \mathrm{~cm}^{-1}, 620 \mathrm{~cm}^{-1}$, $450 \mathrm{~cm}^{-1}$ and $350 \mathrm{~cm}^{-1}$ are observed in the IR spectra (figure 7). These absorption bands are characteristic of $\mathrm{BiO}_{3}$ pyramidal units of the crystalline $\mathrm{Bi}_{2} \mathrm{O}_{3}$. The intensity of these bands, however, decreases and broadens significantly for the glass compositions due to their disordered structure. Thus the IR spectra suggest that the glass compositions consist of $\mathrm{BiO}_{3}$ pyramidal units. The symmetric vibration bands at $830 \mathrm{~cm}^{-1}$ and $450 \mathrm{~cm}^{-1}$ for the glasses have higher wave numbers compared to the vibrational bands of fused $\mathrm{Bi}_{2} \mathrm{O}_{3}$, suggesting that the stronger $\mathrm{Bi}-\mathrm{O}$ bonds are present in the glass compositions caused by the polarization effects. These observations for the binary bismuth cuprate glasses are in sharp contrast to the multicomponent bismuth cuprate glass compositions (Zheng et al 1989), in which both $\mathrm{BiO}_{6}$ octahedral and $\mathrm{BiO}_{3}$ pyramidal units are present depending on compositions. In these glasses with increasing $\mathrm{SrO}$ and $\mathrm{CaO}$ contents, a conversion of $\mathrm{BiO}_{6}$ units to $\mathrm{BiO}_{3}$ units was observed producing nonbridging oxygen atoms. For the $\mathrm{PbO}-\mathrm{CuO}$ glasses, IR bands have been observed at $830 \mathrm{~cm}^{-1}, 620 \mathrm{~cm}^{-1}$ and $460 \mathrm{~cm}^{-1}$ corresponding to the bands of crystalline $\mathrm{PbO}$ and this might be due to $\mathrm{Pb}-\mathrm{O}$ bond vibration in the $\mathrm{PbO}_{4}$ tetrahedra. However, the presence of the band at $720 \mathrm{~cm}^{-1}$, which is absent in either $\mathrm{PbO}$ or $\mathrm{CuO}$, is not clear at the moment.

\subsection{Magnetic properties}

Magnetic susceptibility of all glass compositions showed paramagnetic character of these materials and increased with the increasing transition metal ion. The magnetic properties of these materials arise from the paramagnetic transition metal ions with $3 \mathrm{~d}$ electrons. The concentrations of the reduced transition metal ions estimated from magnetic susceptibility data were found to be ciose to their estimates from the chemical analysis. 


\section{Conclusions}

Glass formation domains and structural properties of some binary transition metal ion glasses based on nonconventional glass network formers $\mathrm{PbO}$ and $\mathrm{Bi}_{2} \mathrm{O}_{3}$ have been studied. Glass formation domains depend on the glass systems as evidenced by $\mathrm{X}$-ray diffraction studies. The composition dependence of density and molar volume shows that the prepared glasses are homogeneous with random network structure. The variation of the glass transition temperature indicates that the strength of the network structure depend on the nature of transition metal ions and glass formers. The structural units building up of these glasses have been obtained from the IR spectra.

\section{Acknowledgement}

The author wishes to thank Mr S Mandal and Mr S Hazra for their help.

\section{References}

Aegerter M, Serra E, Rodingnes A, Kordas G and Moore G 1990 SPIE-Sol-Gel optics, 1328, 361 Bishay A and Maghrabi C 1969 Phys. Chem. Glasses 101

Dimitriev Y, Mihailov V and Gatif E 1986 Phys. Chem. Glasses 34114

Dimitriev Y, Dimitrov V, Arnaudov M and Topalov D 1983 J. Non-Cryst. Solids 57147

Dumbaugh W H 1978 Phys. Chem. Glasses 1921

Dumbaugh W H 1986 Phys. Chem. Glasses 27119

Fajans K and Kreidl N 1948 J. Am. Ceram. Soc. 31105

Ghosh A 1987 Preparation and characterization of some semiconducting glasses from the studies of various physical properties, $\mathrm{Ph} \mathrm{D}$. Thesis, Jadavpur University, Calcutta

Ghosh A 1988 J. Appl. Phys. 642652

Hazra S and Ghosh A 1995 Phys. Ret. B50

Livage J, Jolivet J P and Tronc E $1990 \mathrm{~J}$. Non-Cryst. Solids 12135

Mandal S and Ghosh A 1993 Phys. Rev. B48 9388

Mandal S, Hazra S and Ghosh A 1994 J. Mater. Sci. Lett. 131054

Mandal S, Hazra S, Das D and Ghosh A 1995 J. Non-Cryst. Solids (in print)

Mianxve W and Peinan Z 1986 J. Non-Cryst. Solids 84334

Morikawa $H_{3}$, Jegondez J, Mazieres C and Revolevschi A 1981 J. Non-Cryst. Solids 44107

Nakamura S and Ichinose N 1987 J. Non-Cryst. Solids 95-96 849

Onisi M, Kyoto M and Watanabe M 1991 Jpn. J. Appl. Phys. 30 L988

Kao K J, Wong J and Rao B G 1984 Phys. Chem. Glasses 2557

Sakuri Y and Yamaki J 1990 J. Electrochem. Soc. 132512

Tanaka K, Kamiya K and Yoko T 1989 J. Non-Cryst. Solids 109289

Takahashi Y and Yamaguchi K 1990 J. Mater. Sci. 253950

Tatsumisago M, Tsuboi S, Tohge N and Minami T 1990 J. Non-Cryst. Solids 124167

Yuan L R et al 1991 Jpn. J. Appl. Phys. 30 L1545

Zheng $H$ and Mackenzie J D 1988 Phys. Rev. B38 7166

Zheng H, Xu R and Mackenzie J D 1989 J. Mater. Res. 4911 